\title{
THE ATTITUDES OF MEDICAL STUDENTS TOWARDS CLINICAL RELEVANCE OF HISTOLOGY
}

\author{
Naureen Waseem, Aaqiba Rasheed, Maria Gill*, Ayesha Asad**, Muhammad Omar Shamim, Fatima Waseem*** \\ Islam Medical Colege, Sialkot Pakistan, *Sialkot Medical College, Sialkot Pakistan, **Quetta Institute of Medical Sciences, Quetta/National \\ University of Medical Sciences (NUMS) Pakistan, ${ }^{* * *}$ Allama Iqbal Memorial Hospital, Sialkot Pakistan
}

\begin{abstract}
Objective: To have an insight on student's attitudes regarding clinical relevance of histology in both private andpublic sector medical college (Islam Medical College and Khwaja Safdar Medical College).

Study Design: Cross sectional survey.

Place and Duration of Study: Islam Medical College and Khwaja Safdar Medical College, Sialkot, from Sep to Nov 2019.

Methodology: A cross sectional survey for attitude analysis towards clinical importance of histologywas carried out among 200 third year medical students from private and public sector medical college. Thurdstone and Chave attitude analysis questionnaire was employed to find the attitude score. The questionnaire given to the medical students comprised of 20 statements regarding histology's clinical relevance according to Thurdstone and Chave attitude analysis protocol.

Results: Students of both public and private sector medical college showedscepticism towards the clinical importance of histology. Mean value of attitude score of Islam Medical College is 5.54. Mean value of Khwaja Safdar Medical College is 5.62. There was no marked difference in the attitudes of students of public and private sector medical college. Statistical analysis revealed that the data from a Private and Public sector Medical College were alike with no significant differences. Most data remained on the borderline of the attitude scale employed.

Conclusion: This study provided useful information for the teachers that students do not appreciate the clinical importance of histology much. Students of both public sector and private sector medical college showed doubts about the relevance of histology in their clinical years. Teachers need to devise strategies and help students comprehend the importance of histology.
\end{abstract}

Keywords: Attitude, Clinical importance, Histology, Relevance.

This is an Open Access article distributed under the terms of the Creative Commons Attribution License (http://creativecommons.org/licenses/by/4.0), which permits unrestricted use, distribution, and reproduction in any medium, provided the original work is properly cited.

\section{INTRODUCTION}

Over decades, histology has maintained its essential place in the medical curriculum. Histology is the science of microscopic structures of human tissues and organs. However there has been new advances like digitalization of specimens, virtual microscopy etc, that has reshaped histology teaching in many medical schools. Histology is significant not only for the initial years of medical education to understand the normal structure and function, but it's a backbone for pathology too ${ }^{1}$. Knowledge of histology is essential for understanding the mechanism of disease in terms of changed structure of the human body ${ }^{1}$. Many studies have been conducted

Correspondence: Dr Naureen Waseem, Associate Professor of Anatomy, Islam Medical College, Sialkot Pakistan

Received: 21 Jan 2020; revised received: 09 Mar 2020; accepted: 16 Mar 2020 to report the clinical importance of gross Anatomy $\mathrm{y}^{2,3}$. However there are few studies regarding the importance of histology in the medical curriculum. To date, no studies have been conducted in Pakistan to assess the attitudes of medical students towards the clinical importance of histology. Assessment of attitudes of medical students towards histology will enable anatomy teachers to devise strategies for excellence in academic and clinical competency ${ }^{4}$.

As per PMDC guidelines there are 500 allocated study hours for Anatomy for both 1st and 2nd year, from which half are for the practical content and half for the theory content. Practical content includes histology and gross anatomy labs. In Islam Medical College, on average, 35 hrs of histology lectures and 40 hrs of histology practicals are delivered during an academic year. 
It's the same with the public sector medical college. In terms of teaching methodologies, large group interactive sessions, small group discussions and histology practicals have been employed for teaching histology. Teaching of histology is actually composed of two components, theory and practice. The question is that are we utilizing the time allocated for histology classes effectively to get maximum involvement of students. Do we make the students actively participate in learning. In students perspective the answer is no. Students perceive histology classes as drawing lessons without knowing the importance of understanding microscopic anatomy ${ }^{4}$. The two hours spent in the histology practical are mostly spent in gossiping and sleeping 4 . Measures need to be addressed to ensure the importance of histology as clinically relevant discipline in the medical curriculum ${ }^{4}$.

There is need to reinvent the anatomy curriculum in medical schools as the place of anatomy in medical curriculum has been changed over the past few years 5 . The curricular model chosen must meet the needs of the medical school and the learners ${ }^{6}$. Educators can ensure that students are able to learn what is important and relevant for them by meeting the needs of students7. Getting appropriate feedback from the students by using accurate methods, to assess what has been learned, is crucial for the learning/teaching experience $^{8}$. Although curriculum planning and teaching strategies are decided by the faculty but the opinion of the students need to be taken into account during curriculum making to get out the best outcome ${ }^{9}$. There is some detachment seen between the theory and practice, due to which the students face problems in comprehending histology systemically ${ }^{10}$.

The rationale of the present study is to identify the attitudes of medical students towards the clinical importance of histology. We also compared and reported on the attitudes of students of private and public sector medical college. Identifying student's attitudes, will prove to be valuable in designing effective learning strategies for teaching of microscopic anatomy. The hypothesis of our study was that medical students well regard the clinical relevance of histology.

\section{METHODOLOGY}

The cross-sectional questionnaire-based survey was conducted at a private and public sector medical college of Sialkot, Islam Medical College and Khwaja Safdar Medical College, Sialkot from September 2019 to November 2019. A total of 200 third year medical students of both genders, who gave consent were randomly selected for the survey by convenience sampling. Prevalance was not taken out so we didn't use any calculations for the sample size. Permission was obtained from the selected medical colleges. Ethics approval for the study was obtained from the Institutional Research and Ethics Committee, no 2019$3 / \mathrm{DR}$. The questionnaire given to the medical students comprised of Thurdstone and Chave attitude analysis protocol11. A total of 20 statements regarding histology's clinical relevance was used as devised by Moxham et al12. The statements in the questionnaire were pro-sentiments as well as anti-sentiments, which were randomly arranged, covering a wide range of opinions. The students only tick those statements with which they are in full agreement. For the calculation of each student's attitude score, prior to the study a group of 50 teachers from Anatomy and Pathology were asked to score each statement on the questionnaire between 1-11, where 1 would stand for strongly agree and 11 would stand for strongly disagree. Low values were taken favorable and high values were unfavorable for the attitudes being assessed. The range of score in between represents the diversity of opinion. Each judge independently scored all the statements of the questionnaire Gathering judges evaluations median score of the teachers was calculated, which was used to quantify students' attitudes by providing a numerical value to each statement. The numerical value of each statement were not present in the questionnaires given to the students. To conduct simple calculations Microsoft Excel was used. Mean Comparison of attitudes regarding clinical relevance of histology in both private and public sector medical colleges was 
analysed by independent sample t-test on SPSS16.

\section{RESULTS}

Mean value of attitude score of Islam Medical College is 5.54. Mean value of Khwaja Safdar Medical College is 5.62. There is no significant mean difference in both colleges as shown in table-I. Mean comparison of attitude score regarding Clinical Relevance of Histology in both Public and Private Sector Medical Collegewas difficulty in understanding all the four aspects. The modular system empasis the cinical relvance of the subject which takes into account the gross anatomy $^{3}$. But histology is often ignored by the students thinking tht it is not clinically relevant despite the fact that histology from sthe basis of pathology. Once normal structure is known then a student can appreciate pathological change in structure $^{12}$. Students should have a clear concept about the structure of normal humancells \& tissue for future clinical application ${ }^{10}$.

Table-I: Mean values of attitude scores between imc and KMSMC.

\begin{tabular}{l|c|c|c|c} 
& Colleges & $\mathbf{n}$ & Mean \pm Standard Deviation & Mean Difference \\
\hline \multirow{2}{*}{$\begin{array}{l}\text { Attitude } \\
\text { Scores }\end{array}$} & IMC & 100 & $5.54 \pm 0.688$ & -0.80 \\
\cline { 2 - 5 } & KMSMC & 100 & $5.62 \pm 0.599$ & -0.80
\end{tabular}

Table-II: Mean comparison of attitudes scores.

\begin{tabular}{l|c|c|c|c|c}
\hline Medical College & $\begin{array}{c}\text { Traditional or } \\
\text { Integrated }\end{array}$ & $\begin{array}{c}\text { Total } \\
\text { hours }\end{array}$ & $\begin{array}{c}\text { Practicals } \\
\text { Yes / No }\end{array}$ & $\begin{array}{c}\text { Clinical Teachers } \\
\text { Involved or Not }\end{array}$ & $\begin{array}{c}\text { Clinical Cases } \\
\text { Discussed or Not }\end{array}$ \\
\hline $\begin{array}{l}\text { Islam Medical College } \\
\text { (Private Sector) }\end{array}$ & Traditional & $75 \mathrm{hrs}$ & Yes & Not Involved & Not discussed \\
\hline $\begin{array}{l}\text { KhwajaSafdar Medical } \\
\text { College (Public Sector) }\end{array}$ & Traditional & $80 \mathrm{hrs}$ & Yes & Involved & Discussed \\
\hline
\end{tabular}

analysed by independent sample $t$ test, showing no significant difference between the two colleges as shown in table-II.

Figure-1 \& 2 shows histograms showing students' attitudes towards histology using. Thurdstone and Chave (1951) attitude analysis scale where 1 stands for strongly agree and 11 would stand for strongly disagree.

Statistical analysis reveals that the data from Islam Medical College and Khwaja Safdar Medical College (Private and Public sector Medical College) are alike with no significant differences in frequencies and percentages.

\section{DISCUSSION}

The findings of the study showed that the clinical importance of histology is not appreciated by the medcial students. Both the private and public sector medical students have doubts about the relevance of histology in the clinical years. Anatomy is a composite of four subjects ${ }^{2}$. Teaching as well as learning of Anantomy has been a focus of debate in the past few years because of
These findings were consistent with a similar study done across Europe to find their attitudes towards histology ${ }^{13,14}$. In most medical colleges most of their data remained on the positive side of the attitude scale. Similar studies were done to

Table-III: Main features of histology course in the colleges surveyed.

\begin{tabular}{l|c|c}
\hline \multirow{2}{*}{ Test Variable } & \multicolumn{2}{|c}{ t-test For Equality of Means } \\
\cline { 2 - 3 } & Test Statistics (t) & $p$-value \\
\hline $\begin{array}{l}\text { Student Attitude } \\
\text { (Scores) }\end{array}$ & -0.877 & 0.382 \\
\hline${ }^{*}$ Significant $(p<0.05)$. &
\end{tabular}

find the attitudes towards the clinical relevance of gross anatomy and embryology ${ }^{15}$. In Pakistan still most of the collges are following the traditional system of teaching. The use of modern equipment for teaching and learning is not in use. Traditional histology teaching method using light microscope \& glass slide is practiced for the students within a limited period of time ${ }^{16}$. Still students face difficulty in proper identification of slides \& correlating theory with practical. It becomes responsibility of teachers to know the difficulties 
of the students and solve them. Here comes the role of teachers to make the teaching method easy \& clear for the students, so that they can learn the basic histology within a limited period of practical hour ${ }^{17}$.

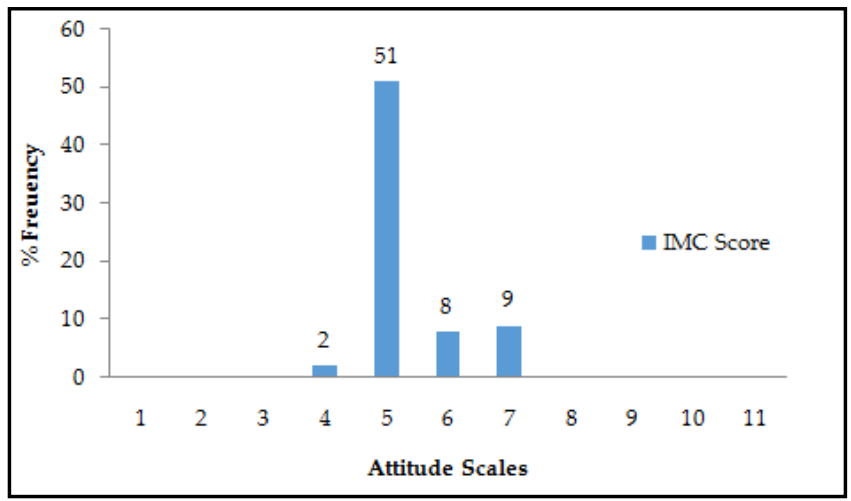

Figure-1: Histogram showing the results obtained from the students of Islam medical college where a score of 1 shows an extremely favorable attitude toward the clinical importance of histology and a score of $\mathbf{1 1}$ an extremely unfavorable attitude.

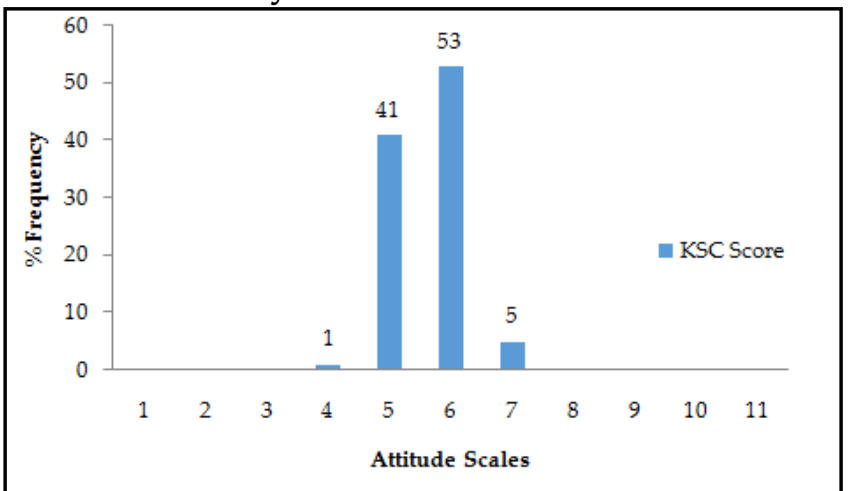

Figure-2: Histogram showing the results obtained from the students of Khwaja Safdar Medical College where a score of 1 shows an extremely favorable attitude toward the clinical importance of histology and a score of $\mathbf{1 1}$ an extremely unfavorable attitude.

The data for the relevance of gross anatomy was quite more positive than embryology and histology when the attitude scale was employed on the European students ${ }^{13}$. Students well appreciate the importance of gross anatomy for their clinical years and safe and efficient medical practice $^{13}$. The results of this study give a clear clue that the stiudnet are not aware of the clinical relevance of histology because the focus is more on passing the exam. The role of assessmt is als very important. Assessments should be designded in an integrated maner so that the students can integrated histology with pathology. Students do not take histology as an important subdivision of Anatomy and crucial for medical education ${ }^{18}$.

The credit hours devoted for histology lectures and practical are almost the same in private and public sector medical college. Teaching too consists of lectures, small group discussions and practicals. There is little or no use of virtual mic-

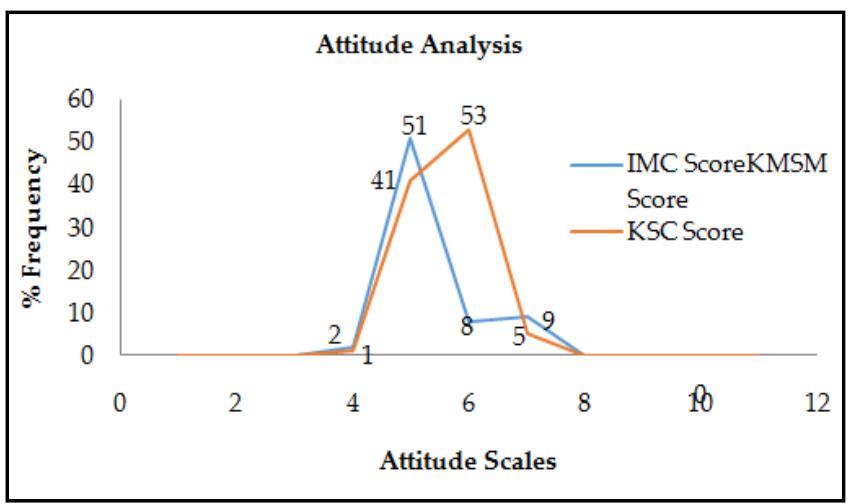

Figure-3: Graphs showing the attitudes of medical students towards the importance histology done by attitude analyses of thurstone \& chave (1951). The attitude scales vary from 1 (extremely positive) to 11 (extremely negative). Blue shows data from islam medical college students. series 2 shows data from the khwaja safdar medical college students.

roscopy ${ }^{16}$. The use of multiheaded microscope in which the teacher are students are simultanousely watching the slide will also create a sense of interest among the studnets. Connecting the microscopes with LEDS will project the microscopic images in a much better way and a bigger picture of the tissue will imprint in the minds of the students ${ }^{18}$. The attitude can be made positive by makig efforts to make the subjects interesting Many quizzes based on microscopic images are available online which can creatsrtitical thinking among the students ${ }^{19}$. The importance of histology must be reinforced by the histology teachers throughout the initial years of medical curriculum and its importance should be stated in the college's curriculum at the beginning of the ses- 
sion. Foster $\mathrm{K}$ has emp-sized the use of e-learning as an aid to learning histology ${ }^{15}$.

Gona et al in his study proved that combined sessions of anatomy teachers and histo-pathologists can also make the subject interesting and clinically relevant ${ }^{16}$. Histology should also be reinforced as a defined short course in third year and fourth year MBBS before they study pathology for better comprehension of the subject. In one study done by Daiz-Perez proved that students interest increased by making material available on the learning management system electronically and making lectures available for students ${ }^{18}$. In one the students mentioned the need for short written instruction by faculty about the topic at the end of practical class (statistically found to be significant). Studies done in United States have shown anatomy teaching strategies have to be modified according to the learning needs of the students ${ }^{19-21}$.

Some studies also show the importance of drawing diagram in histology record during practical hour. A well labelled diagram clears the concepts of the students in an excellent. There is a need that each student should have individual microscope and number of students per batch should be reduced to 8-10 so that they can themselves appreciate the structure of the tissue ${ }^{21}$. Some also mentioned the handling of microscope will help the students in future work to develop skill22,23. Problem based tutorials linking the histology with pathology followed by demonstration of tissue under microscope can also be very useful as has been shown in many countries ${ }^{24,25}$.

The present era requires the integration of basic and clinical subjects in order to prepare better doctor for future. Anatomy is the backbone of basic subjects and none of its component can be ignored if we want ot built doctors for better services for the community.

\section{ACKNOWLEDGEMENT}

Authors express gratitude to Professor Bernard John Moxham for assistance and help. Professor B.J. Moxham; Cardiff School of
Biosciences, Cardiff University, Museum Avenue, Cardiff CF10 3AX,

\section{CONCLUSION}

This study provided useful information for the teachers that medical students do not appreciate the clinical relevance of histology much. Teachers need to make strategies and to work on the students helping them comprehend the relevance of histology. Correct positioning of histology in the basic sciences curriculum is of utmost importance.

\section{CONFLICT OF INTEREST}

The study has no conflict of interest to be declared by any author

\section{REFERENCES}

1. Hussein I, Raad M, Safa R, Jurjus RA, Jurjus A. Once Upon a Microscopic Slide: The Story of Histology. J Cytol Histol 2015; 6(6): $1-5$.

2. Moxham BJ, Plaisant O. Perception of medical students towards the clinical relevance of anatomy. Clin Anat 2007; 20(5): 560-64.

3. Olowo-Ofayoku A, Moxham BJ. Comparisons between the attitudes of medical and dental students toward the clinical importance of gross anatomy and physiology. Clinical Anat 2014; 27(7): 976-87.

4. Jayanthi A, Sarjna MV, Benjamin B. Students' perception of teaching learning method in dissection and histology lab. IOSR J Dental Med Scie 2014; 13(11): 24-28.

5. Louw G, Eizenberg N, Carmichael SW. The place of anatomy in medical education: AMEE Guide no 41. Med Teach 2009; 31(5): 373-86.

6. Singh V, Kharb P. A paradigm shift from teaching to learning gross anatomy: meta-analysis of implications for instructional methods. J Anat Societ Ind 2013; 62(1): 84-89.

7. Ganguly PK. Teaching and Learning of Anatomy in the $21^{\text {st }}$ Century: Direction and the Strategies. Open Med Educat J 2010; 3(1): 5-10.

8. Papa V, Vaccarezza M. Teaching anatomy in the XXI century: new aspects and pitfalls. Scientific World J 2013; 2013(1): 1-5.

9. Nagar SK, Malukar O, Kubavat D, Prajapati V, Ganatra D, Rathwa A. Students' perception on anatomy teaching methodologies. Natl J Med Res 2012; 2(1): 111-12.

10. Lu X, Cheng X, Li K, Lee KK, Yang X. Integration of Histology Lectures and Practical Teaching in China. Inter J Higher Educat 2016; 5(4): 157-64.

11. Thurstone LL, Chave EJ. The Measurement of Attitude: A psychological method and some experiments with a scale for measuring attitude towards the Church. Chicago, IL: University of Chicago Press 1951; 1(1); 405-14.

12. Moxham BJ, Nikoloussi EE, Brenner E, Plaisant O, Brichova $\mathrm{H}$, Kucera $\mathrm{T}$, et al. The attitudes of medical students in Europe toward the clinical importance of histology. Clinical Anat 2017; 30(5): 635-43.

13. Plaisant O, Stephens S, Apaydin N, Courtois R, Lignier B, LoukasM, et al. Medical students' attitudes towards science and gross anatomy, and the relationship to personality. J Anat 2014; 224(3): 261-69. 
14. Moxham BJ, Nikoloussi EE, Standley H, Brenner E, Plaisant O, BrichovaH, et al. The attitudes of medical students in Europe toward the clinical importance of embryology. Clinical Anat 2016; 29(2): 144-50.

15. Foster K. Medical education in the digital age: Digital whole slide imaging as an e-learning tool. J Pathol Inform 2010; 12(1): $1-10$.

16. Gona AG, Berendsen PB, Alger EA. "New Approach to Teaching Histology" Med Sci Educat 2012; 15(1): 78-89.

17. Coleman R. Can histology and pathology be taught without microscopes. The advantages and disadvantages of virtual histology, Acta Histochemica 2009; 111(2): 1-4.

18. Daiz-Perez JA, Raju S, Julio ADP, Sharat R, Echeverri JH. Evaluation of a teaching strategy based on integration of clinical subjects, virtual autopsy, pathology museum, and digital microscopy for medical students. J Pathol Inform 2014; 5(1): 25-28.

19. Bandyopadhyay R, Biswas R. Students' Perception and Attitude on Methods of Anatomy Teaching in a Medical College of West Bengal, India. J Clin Diagn Res 2017; 11(9): AC10-12.
20. Drake RL, McBride JM, Pawlina W. An update on the status of anatomical sciences education in United States medical schools. Anat Sci Edu 2014; 7(4): 321-25.

21. Moxham BJ, Moxham SA. The relationships between attitudes, course aims and teaching methods for the teaching of gross anatomy in the medical curriculum. Europ J Anat 2016; 11(S1): 19-30.

22. Patel KM, Moxham BJ. Attitudes of professional anatomists to curricular change. Clin Anat 2006; 19(2): 132-41.

23. Waterston SW, Stewart IJ. Survey of clinicians' attitudes to the anatomical teaching and knowledge of medical students. Clin Anat 2005; 18(5): 380-84.

24. Magid MS. Consensus guidelines for practical competencies in anatomic pathology and laboratory medicine for the undifferentiated graduating medical student. Acad Pathol 2015; 2(4): 1-17.

25. Diaz-Perez JA. Evaluation of a teaching strategy based on integration of clinical subjects, virtual autopsy, pathology museum, and digital microscopy for medical students. J Pathol Inform 2014; 5(1): 25-28. 